www.jmscr.igmpublication.org

Impact Factor 5.84

Index Copernicus Value: 83.27

ISSN (e)-2347-176x ISSN (p) 2455-0450

crossref DOI: _https://dx.doi.org/10.18535/jmscr/v5i7.128

Journal Of Medical Science And Clinical Research

IGM Publication

An Official Publication of IGM Publication

\title{
Comparative Study between Exteriorization of Uterus during Caesarean Section versus Intra Peritoneal or In-Situ Repair
}

\author{
Authors \\ Dr Deepali Jain ${ }^{1}$, Dr Mukhram Devanda ${ }^{2}$, Dr Narendra Mahavar ${ }^{3}$, Dr Ajay Sharma ${ }^{4}$, \\ Dr Sandhya Choudhary ${ }^{5}$, Dr Meenakshi Samriya ${ }^{6}$ \\ ${ }^{1}$ Senior Professor, Department of Obstetrics \& Gynaecology, J.L.N Medical College, Ajmer, Rajasthan \\ ${ }^{2}$ P.G. Student, Dept. Of Obstetrics \& Gynaecology, J.L.N Medical College, Ajmer, Rajasthan \\ Email: mukhramdevanda@gmail.com \\ ${ }^{3,4,5,6}$ Assistant Professor, Dept. Of Obstetrics \& Gynaecology, J.L.N Medical College, Ajmer, Rajasthan
}

\section{Introduction}

Caesarean delivery defines the birth of a foetus via laparotomy and then hysterotomy. It is the delivery of an infant, alive or dead, through an abdominal uterine incision after period of viability. From 1996 to 2011, the caesarean delivery rate in United States increase from $20 \%$ of all deliveries to $33 \%$. In India rate of the caesarean section raised $17.2 \%$ in $2015-16$ (NFHS-4) in relation to $8.5 \%$ in 2005-06 (NFHS-3) data. Cesarean section rate in Rajasthan in $2015-16$ was $8.6 \%$ as compare to $3.8 \%$ in 2005-06 (Source NFHS-3). ${ }^{1}$

A figure below $5 \%$ implies that a substantial proportion of woman do not have access to surgical obstetric care; on the other hand a rate higher than 15 percent indicate over utilization of the procedure for other than life saving reason (WHO;2010). The level of caesarean section is well above the mentioned WHO ratio of $15 \%$ for many of the countries, and it is increasing over the time. $^{1}$

In this contest the rapid increase of CS rate throughout world has become a serious public health issue because several studies have found that the high rate of caesarean section delivery does not necessarily contribute to an improved maternal health and pregnancy outcome. ${ }^{2}$

Various studies on the technique of performing caesarean section have focused on reducing the operating time, blood loss, wound infection. Many variations in the surgical techniques for caesarean section have been proposed. ${ }^{2}$ They aim at reducing the surgical time, surgical cost, postoperative morbidity, adverse effects and hospital stay.

Majority of the surgeons prefer to suturing of the uterus, lying within the abdomen (intra peritoneal or in-situ repair). But this common practice of insitu repair has the short comings of poor accessibility of lower uterine segment, thus in effective suturing leading to more blood loss. An increasing number of surgeons now a days choose to exteriorize the uterus. Exteriorisation has been described to facilitate easy repair of uterine incision when exposure is difficult and when there are problems with haemostasis. Initially the technique of exteriorisation of uterus was not popular because of hypothesised danger of the technique. These include vomiting, pain, and 
hemodynamic instability. In this context we performed the current study with the aim of comparing the advantages and disadvantages of exteriorisation by analysis of 130 cases each with regard to operating time, blood loss, need for emergency blood transfusion, intraoperative pain, vomiting, wretching and postoperative changes in Hematocrit value. $^{3}$

\section{Material \& Methods}

A randomised clinical trials, comparing uterine exteriorisation with intraabdominal repair of uterine incision in caesarean section was conducted in the Department of Obstetrics and Gynaecology, JLN Medical College, Ajmer at Zanana Hospital on 130 Patients admitted in ward during June 2015 to July 2016. Written informed consent by each was sought before the study.

\section{Inclusion Criteria}

Women undergoing caesarean section either elective or emergency under spinal anaesthesia.

\section{Exclusion Criteria}

Patients with heart disease, chorioamnionitis and third trimester haemorrhage.

All the cases that met inclusion and exclusion criteria were randomly allocated into 2 interventional group by Chit Box Method:-

Group A (Study Group)- 65 patients under the exteriorisation of uterus for repair during caesarean section.

Group B (Control Group)- 65 patients undergone caesarean section whom uterus was repaired intraabdominally.

All the caesarean section was done by a single surgeon to eliminate Bias. All the results were statistically analysed.

\section{Measurement during following stages are :}

Preoperatively - We will measure heart rate, P.R. \& Blood pressure.

Intraoperatively checked: heart rate, blood pressure after induction of anaesthesia, during surgery, on exteriorization of uterus, during repair of uterus and after reposition of the uterus inside the peritoneal cavity. All other intra-operative difficulties encountered like problem of exposure of incision site, wound extension, hematoma and PPH was also noted.

Postoperatively we looked for Degree of $\mathrm{Hb}$ fall before and after surgery.

\section{Results}

The present study observed that most of the cases in both groups belonged to age group between 20 $30 \mathrm{yrs}, 84.62 \%$ in study group and $87.99 \%$ in control group (table 1). The most frequent indication for caesarean section is previous caesarean section in our study. 27 (41.54\%) patients in both groups were taken for this indication. Next in the line are breech, failed induction, CPD and fetal distress followed by previous 2 LSCC etc (table 2).

The mean difference between preoperative $\mathrm{Hb}$ and III $^{\text {rd }}$ postoperative day $\mathrm{HB}$ in study group is $0.9262 \pm 0.574$, in control group is $1.842 \pm 0.7943$ the difference is highly significant $(\mathrm{P}<0.001)$ (table 3). The mean decrease in the 2 days hematocrit in study group is $3.306 \pm 2.236$ and in control group $5.037 \pm 2.464$. The difference is significant $(\mathrm{P}<0.001)$ (table 4$)$.

In our study, 5 out of 65 cases (7.69\%) and 15 out of 65 controls $(23.08 \%)$ had febrile morbidity. It means febrile morbidity is less common in exteriorisation group because difference is significant $(\mathrm{P}=0.029)$. It is attributed to reduced operating time (table 5).

Our study wound complications in the form of infection, hematoma, breakdown is found in $3(4.62 \%)$ out of 65 cases and 5(7.69\%) out of 65 control which is not statistically significant $(\mathrm{P}=$ $0.715)$ and occurrence of urinary tract infection is in $3(4.62 \%)$ cases and $5(7.69 \%)$ controls. The difference in this outcome also does not come out to be significant $(\mathrm{P}=0.715)$ (table $6 \& 7)$. 
Table -1:_Distribution of Cases according to Age

\begin{tabular}{|l|c|c|c|c|c|c|}
\hline Groups & N & Mean & S.D. & Median & Range & P-Value \\
\cline { 1 - 5 } Study & 65 & 25.54 & 3.759 & 25 & $20-38$ & 0.352 \\
\hline Control & 65 & 24.95 & 3.361 & 25 & $18-35$ & \\
\hline
\end{tabular}

Table -2: Distribution of Cases according to indications of Caesarean Sections

\begin{tabular}{|l|c|c|c|}
\hline Indication & Study & Control & Total \\
\hline Previous LSCS & 27 & 27 & 54 \\
& $(41.54 \%)$ & $(41.54 \%)$ & $(41.54 \%)$ \\
\hline CPD & 5 & 5 & 10 \\
& $(7.69 \%)$ & $(7.69 \%)$ & $(7.69 \%)$ \\
\hline Breech & 7 & 6 & 13 \\
& $(10.77 \%)$ & $(9.23 \%)$ & $(10.00 \%)$ \\
\hline PROM & 1 & 1 & 2 \\
& $(1.54 \%)$ & $(1.54 \%)$ & $(1.54 \%)$ \\
\hline Failed Induction & 5 & 7 & 12 \\
& $(7.69 \%)$ & $(10.77 \%)$ & $(9.23 \%)$ \\
\hline Previous 2 LSCS & 3 & 5 & 8 \\
& $(4.62 \%)$ & $(7.69 \%)$ & $(6.15 \%)$ \\
\hline BOH & 2 & 2 & 4 \\
& $(3.08 \%)$ & $(3.08 \%)$ & $(3.08 \%)$ \\
\hline Unstable Lie & 2 & 2 & 4 \\
& $(3.08 \%)$ & $(3.08 \%)$ & $(3.08 \%)$ \\
\hline Foetal Distress & 5 & 4 & 9 \\
& $(7.69 \%)$ & $(6.15 \%)$ & $(6.92 \%)$ \\
\hline NPOL & 4 & 3 & 7 \\
& $(6.15 \%)$ & $(4.62 \%)$ & $(5.38 \%)$ \\
\hline S.Oligo & 2 & 2 & 4 \\
& $(3.08 \%)$ & $(3.08 \%)$ & $(3.08 \%)$ \\
\hline S.PIH & 2 & 1 & 3 \\
& $(3.08 \%)$ & $(1.54 \%)$ & $(2.31 \%)$ \\
\hline Total & 65 & 65 & 130 \\
& $(100.00 \%)$ & $(100.00 \%)$ & $(100.00 \%)$ \\
\hline
\end{tabular}

Chi- Square $=1.498$ with 11 Degrees of freedom; $\mathrm{P}=1.000$

Table 3 Comparison of Uterine Exteriorisation versus In situ repair outcome $-3^{\text {rd }}$ Postoperative day Drop in $\mathrm{Hb}$

\begin{tabular}{|l|c|c|c|c|c|c|}
\hline Group & $\mathrm{N}$ & Mean & S.D. & Median & Range & P. Value \\
\hline Study & 65 & 0.9262 & 0.574 & 0.8 & $0.1-2.4$ & \multirow{2}{*}{$<0.001$} \\
\hline Control & 65 & 1.842 & 0.7943 & 1.8 & $0.3-4.2$ & \\
\hline
\end{tabular}

Table 4 Comparison of Uterine Exteriorisation versus in situ Repair outcome $-3^{\text {rd }}$ Postoperative day Drop in Hematocrit

\begin{tabular}{|l|c|c|c|c|c|c|}
\hline Group & $\mathrm{N}$ & Mean & S.D. & Median & Range & P. Value \\
\hline Study & 65 & 3.308 & 2.236 & 2.9 & $0-9.2$ & $<0.001$ \\
\hline Control & 65 & 5.037 & 2.464 & 5.3 & $0-13.5$ & \\
\hline
\end{tabular}

Table - 5: Comparison of Uterine Exteriorisation versus in situ repair outcome - Febrile Morbidity

\begin{tabular}{|l|c|c|c|}
\hline Febrile Morbidity & Study & Control & Total \\
\hline Present & 5 & 15 & 16 \\
& $(7.69 \%)$ & $(23.08 \%)$ & $(12.31 \%)$ \\
\hline Absent & 60 & 50 & 114 \\
& $(92.31 \%)$ & $(76.92 \%)$ & $(87.69 \%)$ \\
\hline Total & 65 & 65 & 130 \\
& $(100.00 \%)$ & $(100.00 \%)$ & $(100.00 \%)$ \\
\hline
\end{tabular}

Chi-Square $=4.786$ with 1 Degree of Freedom; $\mathrm{P}=0.029$ 
Table - 6: Comparison of Uterine Exteriorisation versus in situ repair outcome - Urinary Tract Infection (Cystitis)

\begin{tabular}{|l|c|c|c|}
\hline UTI & Study & Control & Total \\
\hline Present & 3 & 5 & 8 \\
& $(4.62 \%)$ & $(7.69 \%)$ & $(6.15 \%)$ \\
\hline Absent & 62 & 60 & 122 \\
& $(95.38 \%)$ & $(92.31 \%)$ & $(93.85 \%)$ \\
\hline Total & 65 & 65 & 130 \\
& $(100.00 \%)$ & $(100.00 \%)$ & $(100.00 \%)$ \\
\hline
\end{tabular}

Chi Square $=0.133$ with 1 Degree of Freedom; $\mathrm{P}=0.715$.

Table - 7: Comparison of Uterine Exteriorisation versus in situ repair outcome - Wound Complications (Infection, Hematoma, wound dehiscence)

\begin{tabular}{|l|c|c|c|}
\hline UTI & Study & Control & Total \\
\hline Present & 3 & 5 & 8 \\
& $(4.62 \%)$ & $(7.69 \%)$ & $(6.15 \%)$ \\
\hline Absent & 62 & 60 & 122 \\
& $(95.38 \%)$ & $(92.31 \%)$ & $(93.85 \%)$ \\
\hline Total & 65 & 65 & 130 \\
& $(100.00 \%)$ & $(100.00 \%)$ & $(100.00 \%)$ \\
\hline
\end{tabular}

Chi Square $=0.133$ with 1 Degree of Freedom; $\mathrm{P}=0.715$.

\section{Discussion}

The most frequent indication for caesarean section is previous caesarean section in our study. 27 (41.54\%) patients in both groups were taken for this indication. Thus the 2 groups are comparable with respect to indications of caesarean section. In the study by Sood Atul Kumar et $\mathrm{al}^{4}$ the 2 groups did not differ with respect to indication for caesarean section or various high risk factors. Similarly, in Coutinho et $\mathrm{al}^{5}$ study the 2 groups were similar in indications for caesarean section. He excluded patients with 2 or more caesarean delivery, chorioamnionitis, third trimester haemorrhage, previous abdominal surgery.

The mean difference between preoperative $\mathrm{Hb}$ and III $^{\text {rd }}$ postoperative day $\mathrm{HB}$ in study group is $0.9262 \pm 0.574$, in control group is $1.842 \pm 0.7943$ the difference is highly significant $(\mathrm{P}<0.001)$. The mean decrease in the 2 days hematocrit in study group is $3.306 \pm 2.236$ and in control group $5.037 \pm 2.464$. The difference is significant $(\mathrm{P}<$ 0.001).

Sood Atul Kumar et $\mathrm{al}^{4}$ found significant intraoperative blood loss in the study group as compared to controls group $(\mathrm{P}<0.05)$. Mean postoperative haemoglobin decrease was significantly lower in the study group as compared to control group $(0.85 \mathrm{gm} / \mathrm{dl} \pm 0.27$ and 0.93 $\mathrm{gm} / \mathrm{dl} \pm 0.25$ respectively. $\mathrm{P}<0.05)$. Similarly, Ezechil OC et al ${ }^{6}$ found significant difference in the estimated blood loss which was less in exteriorised group $(\mathrm{P}=0.009)$ and postoperative anaemia rate were significant less in exteriorised group $(\mathrm{P}=0.028)$. MA Wahad, $\mathrm{P}$ Karantzis et $\mathrm{al}^{7}$ from their study stated that exteriorisation of uterus had a statistically significant association with reduced blood loss $(\mathrm{P}<0.05)$.

Our results contradict with Edi Osagie et $\mathrm{al}^{8}$, have found that although there were no significant differences in hemodynamic parameters, exteriorisation was associated with a smaller reduction in postoperative hematocrit values.

Orji FO et $\mathrm{al}^{9}$ after assessing intraoperative and postoperative morbidity following exteriorisation of uterus compared to non-exteriorisation found significant reductions blood loss in the study group $(\mathrm{P}<0.05)$.

Coutinho et $\mathrm{al}^{5}$ reported by their trial that blood loss estimated by pre and postoperative hematocrit was similar in both groups. Similarly, Colin A Waish ${ }^{10}$ found no difference in amount of blood loss when compared the two groups.

But, Mughina Siddiqui et $\mathrm{al}^{11}$ when compared the intraoperative complications between exteriorisation and in situ repair group found that the estimated blood loss was similar between the two 
groups. Similarly, Nafisi $\mathrm{S}^{12}$ an anaesthesiologist reported by his trial that the postoperative haemoglobin levels were similar between the groups.

Further, Jose Carvalho et $\mathrm{al}^{13}$ in the same year found no difference in the amount of blood loss between the 2 groups. This shows that the postoperative drop in haemoglobin and hematocrit is greater in the in situ group than in the exteriorised group $(\mathrm{P}<0.001)$. It means in situ repair leads to greater intraoperative blood loss than exteriorised groups when all other factors are comparable.

Ozbay $\mathrm{K}$ et $\mathrm{al}^{14}$ studied that there was no significant difference in drops in hemoglobin or hematocrit levels. Dr. K.K. Das et $\mathrm{al}^{15}$ studied that the perioperative fall in haemoglobin was less in the exteriorized group. The mean fall in haemoglobin was 0.9820 for in-situ group and 0.5360 for exteriorization group. The $\mathrm{P}$ value for perioperative fall in hemoglobin was <0.0001 which is considered statistically significant.

This shows the incidence of febrile morbidity between the 2 groups i.e. symptoms due to a temperature of above $37.5^{\circ} \mathrm{C}$ on at least 2 consecutive reading done at least 6 hours apart. It means febrile morbidity is less common in exteriorisation group because difference is significant $(P=0.029)$. It is attributed to reduced operating time. Significant lower febrile morbidity reported in this is similar to that reported by others.

Earlier work showed a substantial reduction in the rate or postoperative infection and morbidity with exteriorisation of the uterus. Hershey DW et $\mathrm{al}^{16}$ found in his study that febrile morbidity was less common in this exteriorised group (RR $0.41 .95 \%$ CI 0.17 to 0.97). This finding was statistical significant. Sood Atul Kumar et $\mathrm{al}^{4}$ got febrile morbidity of $9.9 \%$ in study group and $23 \%$ in control group which was significant $(\mathrm{P}<0.05)$ similar to our study.

Xiong et $\mathrm{al}^{17}$ showed no difference in the incidence between the 2 groups similar to MA Wahab, P Karantzis et al. ${ }^{7}$ Similarly Nafisi $\mathrm{S}^{12}$,
Orji FO et $\mathrm{al}^{9}$, Colin A Walsh ${ }^{10} \&$ Dr. K.K. Das et $\mathrm{al}^{15}$ found no statistically difference in occurrence of fever between the 2 groups.

In our study wound complications in the form of infection, hematoma, breakdown is found in $3(4.62 \%)$ out of 65 cases and 5(7.69\%) out of 65 control which is not statistically significant $(\mathrm{P}=$ 0.715 ) and occurrence of urinary tract infection is in $3(4.62 \%)$ cases and $5(7.69 \%)$ controls. The difference in this outcome also does not come out to be significant $(\mathrm{P}=0.715)$. Similarly Sood Atul Kumar et $\mathrm{al}^{4}$ found in significant trend toward decreased infections morbidity in the form of endomyometritis cystitis and wound infection in exteriorisation. He found cystitis in $2.7 \%$ case and $7.4 \%$ control $(\mathrm{P}<0.05$, Or $=0.35)$ wound infection in $2.7 \%$ case and $6.4 \%$ controls $(\mathrm{P}<$ 0.05, Or $=0.40$ ). Also Cochrane systematic review showed no difference in the incidence of wound infections.

Ma Wahab et $\mathrm{al}^{7}$, Nafisi $\mathrm{S}^{12}$ also did not found any difference in wound infection between the 2 group. Further, Countinho et $\mathrm{al}^{5}$ reported no statistically significant difference between 2 groups concerning the rate of surgical site infection $(7.1 \%$ in cases as compared to $8.7 \%$ in controls). Dr. KK Das ${ }^{15}$ found that there was no significant difference between study and control group in relation to wound complication and cystitis.

\section{Conclusion}

The striking difference between the two groups were noted for perioperative blood loss, operating times and postoperative febrile morbidity which were all less in external repair group. Personal preference for performing a determined technique is the main guide for choice because in either technique some data justify a choice. One should be trained in both techniques because some situations obligate the surgeon to use one or the other.

\section{References}

1. Anderson ER, Gates S. Techniques and materials for closure of the abdominal wall 
in caesarean section. Cochran Database Syst Rev. 2004: CD004663.

2. Antonella Cromi Md. PHD et al Blunt expansion of the low transverse uterine incision at caesarean delivery: a randomized comparison of 2 techniques. America Journal of Obstetrics \& Gynaecology, Sept 2008; Vol. 199: Pg. 292-294.

3. Bujold E, Bujold C, Hamilton EF, Hanel F, Gauthier RJ. The impact of a single layer or double layer closure on uterine rupture Am J Obstet. Gynecol. 2002; 186: 1326-30.

4. Sood Atul Kumar. Exteriorisation of uterus at caesarean section. J Obstet Gynaecol, July/Aug 2003; Vol. 53. No. 4: pg. 353-358.

5. Coutinho IC, Ronios de Amorin MM, Katz L, Bandeira de Feraz AA. Uterine exteriorisation compared with in situ repair at caesarean delivery: a randomized controlled trial. Jr of Obstet Gynecol. 2008 Jul; 112(1): 183.

6. Ezechi OC, Kalu BK, Njokanma FO, Mwokoro CA, Okeke GC, Uterine incision closure at caesarean section : a randomised comparative study of intra peritoneal closure and closure after temporary exteriorisation. West Afr J Med, 2005 JanMarch, 24(1): 41-3.

7. MA Wahab, P Karantzis. A randomized controlled study of uterine exteriorisation and repair at caesarean section. British Journal Obstetrics and Gynaecology, 1999; Vol. 106, Issue 9, pg 913-916.

8. Edi Osagie EC, Hopkins RE, Ogdo V et al Uterine exteriorisation at caesarean section infiuence on maternal morbidity. $\mathrm{Br} \mathrm{J}$ Obstet Gynaecol. 1998; 105: 1070-1078.

9. Orji Fo, Olaleye AO, Loto OM, Ogunniyn SO. A randomized controlled trial of Uterine exteriorisation and nonexteriorisation at caesarean section. Aust
NZJ Obstet Gynaecol, 2008 Dec; 48(6): 570-4.

10. Colin A Walsh, Stewart R Walsh. Extraabdominal v/s intraabdominal uterine repair at caesarean delivery: a meta analysis. American Journal of Obstetrics and Gynaecology, June 2009; 200(6): 625e1-625e8.

11. Mughina Siddiqui MD et al. Complications of Exteriorisation versus insitu uterine repair at caesarean section Canadian Journal of Anaesthesia, 2004: 52(139): 730-1000.

12. Nafisi S. Influence of uterine exteriorisation versus insitu repair on post caesarean maternal pain: a randomized trial. Int J Obstet Anesth. 2007 April. 16 (2): 135-8.

13. JC Carvalho. Siddiqui M, Goldszmidt E, Fallah S. Complications of exteriorisation compared with in situ uterine repair at caesarean delivery under spinal anaesthesia: a randomised controlled trial. Obstet. Gynaecol, 2007 Sept; 110(3):570-5.

14. Ozbay K et al. Exteriorized versus in-situ repair of the uterine incision at caesarean delivery: a randomized controlled trial. Clin Exp Obstet Gynecol. 2011;38(2):1558.

15. Dr. K.K. Das et al. Comparative Study between Exteriorization of Uterus during Caesarean Section versus Intraperitoneal or in-Situ Repair. Sch. J. App. Med. Sci., October 2015; 3(7D):2724-2728.

16. Hershey DW, Quilligan EJ Uterine exteriorisation at caesarean section. Obstet Gynaecol. 1978; 52: 189-92.

17. Xiong Quing et al: Uterine repair with exteriorisation or insitu at caesarean section: A randomized controlled trial. Chinese Journal of Evidence Based Medicine, 2004; 09-25, pg 615-619. 